\title{
VASIJAS NEGRAS PULIDAS: UNA VARIEDAD DE LA CERÁMICA TARDÍA DEL VALLE CALCHAQUÍ
}

Lidia Baldini y Marina Sprovieri ${ }^{1}$

\section{$*$ Introducción}

Resumen

Durante el período de Desarrollos Regionales en el valle Calchaquí (Salta, Argentina) a la alfarería de tipo santamariano-calchaquí se asocia recurrentemente una variedad de superficies negras pulidas escasamente tratadas. Analizamos una muestra que proviene principalmente

del sitio La Paya, obtenida por Ambrosetti (1907), y consideramos

información sobre otros asentamientos cercanos, como El Churcal, y sobre alfarería similar de la Quebrada del Toro. Su caracterización a partir de la morfología permitió identificar 13 formas correspondientes a escudillas, ollas, botellas, cuencos y platos. En éstas se distinguió la ausencia de algunas formas de las vasijas de tipo santamariano-calchaquí. Finalmente, consideramos posibles vinculaciones con otras regiones.

Palabras claves: alfarería - valle Calchaquí - período de Desarrollos Regionales - período Inca. Santamariano-calchaquí pottery described for the Regional Developments period in the Calchaquí Valley (Salta, Argentina) is recurrently

found in association with pottery that has black polished surfaces. The latter having been scarcely considered, we contrast samples from the La Paya site originally produced by Ambrosetti (1907), with those obtained from El Churcal and Quebrada del Toro sites, nearby, where similar pottery was found. Morphological characterization enabled for the identification of 13 shapes of bowls, pots, bottles and plates. The relative absence of Santamariano-calchaquí shapes leads to infer on interregional connections.

Key words: pottery - Calchaquí Valley - Regional Developments period - Inca period.

Recibido: septiembre 2008. Aceptado: mayo 2009
El interés por la investigación arqueológica del valle Calchaquí (provincia de Salta, Argentina) se inicia a fines del siglo XIX y alcanza un importante avance en las primeras décadas del siguiente. Las expediciones organizadas por la Facultad de Filosofía y Letras de la Universidad de Buenos Aires y dirigidas por Ambrosetti en 1906 y 1907 fundan la arqueología regional; los trabajos de mayor magnitud son realizados en el sitio La Paya, donde excava, registra y analiza minuciosamente el contenido de 203 entierros, concluyendo que pertenecen a "una cultura típica local" (Ambrosetti 1907:529).

La alfarería decorada de las sociedades tardías del valle Calchaquí, es decir, las correspondientes al período de Desarrollos Regionales (siglos IX a XV) ${ }^{2}$ y a la época de ocupación inca, recibió atención desde entonces. Sin embargo, otras clases de cerámica recurrentemente asociadas a aquélla fueron objeto de descripciones más generales. Entre estas últimas se encuentra una variedad de vasijas de superficies negras y pulidas. En esta oportunidad, abordamos su caracterización analizando una muestra que proviene principalmente del sitio La Paya, aunque también consideramos información bibliográfca sobre otros asentamientos cercanos, particularmente de El Churcal, y sobre alfarería similar registrada en sitios tardíos de la Quebrada del Toro (Boman 1908; Raffino 1972; Cigliano 1973).

\footnotetext{
${ }^{1}$ CONICET. Paseo del Bosque s/nº, 1900, La Plata, ARGENTINA. Email: lbaldini@fcnym.unlp.edu.ar / lbaldini@ciudad.com.ar; Email: msprovierifcnym.unlp.edu.ar

2 El período de Desarrollos Regionales - también conocido como Intermedio Tardío- es la época en que se alcanzaron los mayores niveles de desarrollo sociopolítico, económico y demográfico en los siglos previos a la conquista española. El registro material indica una concentración poblacional en asentamientos conglomerados, grandes obras de infraestructura agrícola, incremento de la producción de bienes elaborados con gran inversión de trabajo, e integración de estilos regionales, entre otros.
} 
Nuestro análisis pretende identificar y sistematizar la variabilidad total de formas que se percibe tanto en descripciones de piezas completas como a partir de fragmentos. Una vez definida dicha variabilidad de acuerdo a un criterio uniforme, la correlacionamos con las distintas categorías de formas descritas para esta cerámica negra por diferentes autores a partir de muestras de La Paya y de otros sitios de la región. De este modo, obtuvimos una visión más homogénea de toda la gama de formas de esta producción cerámica de las sociedades calchaquíes tardías.

Identificamos 13 formas correspondientes a escudillas, escudillas hondas, ollas, botellas, platos, cuencos y platos hondos (Balfet et al. 1983). Estas formas muestran cierta diferencia con la morfología de las vasijas de tipo santamariano-calchaquí, de manera que investigamos las posibles vinculaciones con otras regiones, como por ejemplo la Quebrada del Toro.

\section{* Variedades alfareras tardías del valle calchaquí}

Como mencionamos, la cerámica tardía del valle Calchaquí recibió atención tempranamente. Ambrosetti (1902) y Boman (1908) presentan los materiales que obtuvieron mediante compras a pobladores locales que los habían extraído de la Casa Morada de La Paya. La Paya, a unos $10 \mathrm{~km}$ al sur de Cachi (Figura 1), es un asentamiento conglomerado con viviendas de muros de piedra y plantas rectangulares o cuadrangulares, surcado por vías de movilidad y en el que se inscribe la construcción identificada como Casa Morada. Esta corresponde a un recinto de planta rectangular de aproximadamente $13 \times 4 \mathrm{~m}$, con características arquitectónicas netamente incas. A diferencia del resto de los recintos del sitio fue construida con bloques regulares de areniscas rojas que no se encuentran en el entorno inmediato. Fue emplazada al interior de un recinto preexistente en la parte más alta del asentamiento, sector que fue parcialmente remodelado durante la época inca (Ambrosetti 1907; González y Díaz 1992).

El área de viviendas está rodeada por un muro, fuera del cual, hacia el oeste, se emplaza el cementerio. Estos espacios fueron denominados por Ambrosetti (1907) "Ciudad" y "Necrópolis", respectivamente (Figura 2).

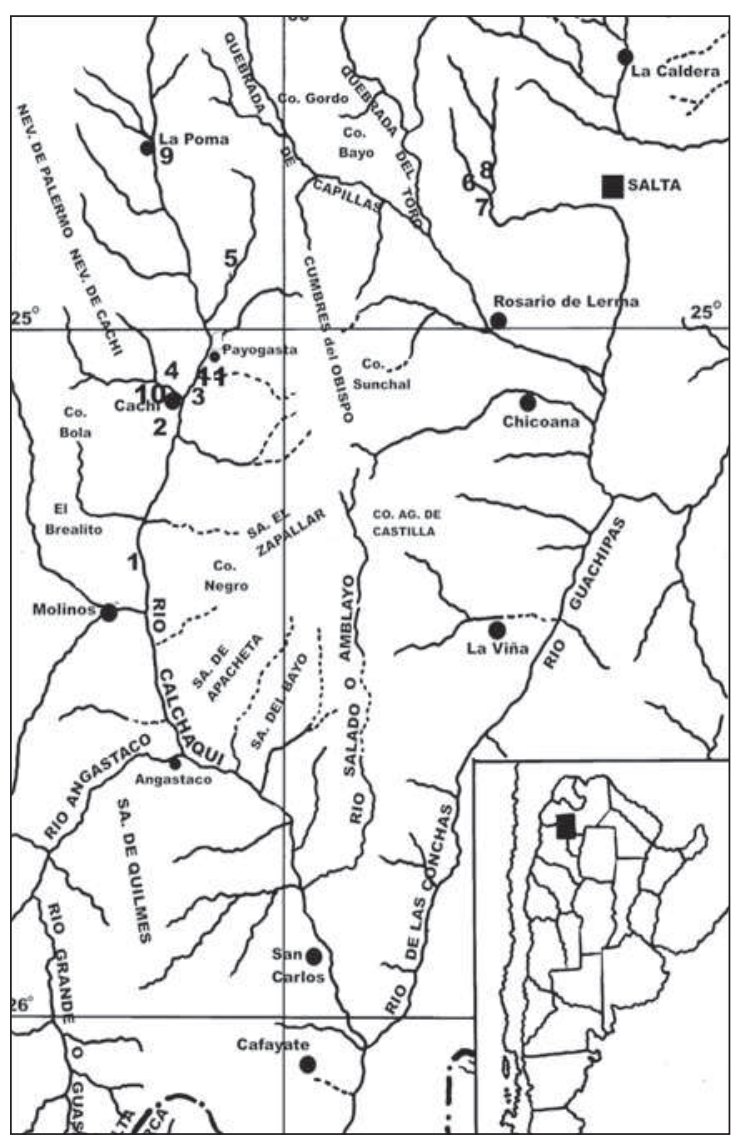

Figura 1. Mapa de un sector del Noroeste Argentino, con la ubicación de los sitios arqueológicos: 1) El Churcal; 2) La Paya;

3) Kipón; 4) Borgatta; 5) Potrero de Payogasta; 6) Tastil;

7) Puerta de Tastil; 8) Morohuasi; 9) La Poma; 10) Tero;

11) Ruiz de Los Llanos.

Aunque las investigaciones se centraron en la búsqueda y excavación de tumbas, en el asentamiento se realizaron unas pocas excavaciones en los ángulos interiores de algunos recintos, donde se hallaron sectores con capas de cenizas y carbones, y vasijas ordinarias y decoradas, que en ciertos casos, correspondían a enterratorios de niños.

Ambrosetti efectuó una detallada descripción y clasificación de la cerámica hallada en el sitio, identificando una serie de vasijas de superficies negras pulidas, con variaciones al gris y parduzco. Entre estas vasijas distingue un conjunto de vasos negros, poco frecuentes frente a otro de pucos negros, al que considera "la pieza de alfarería más común en los sepulcros de La Paya” (Ambrosetti 1907:309). 

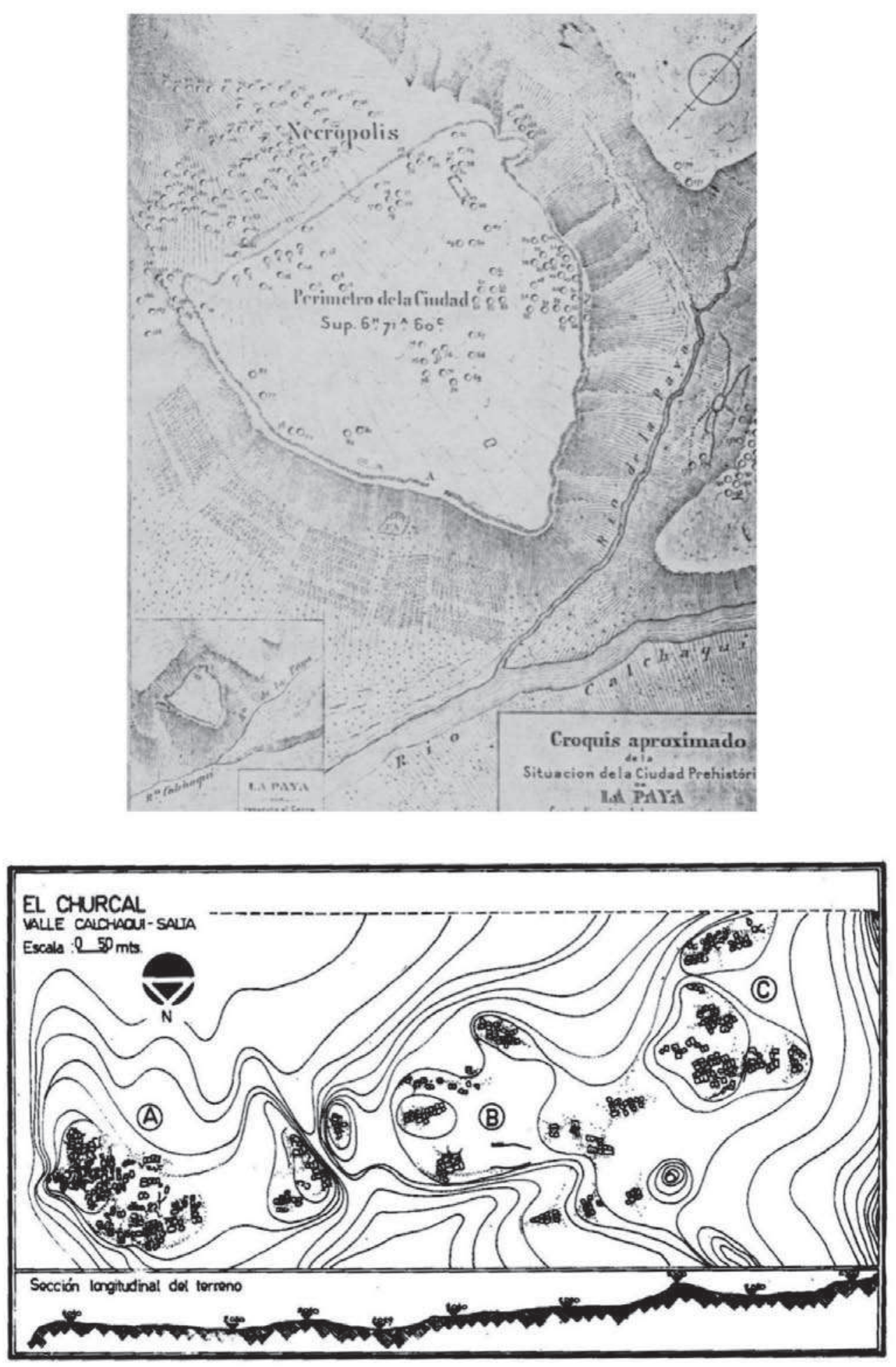

Figura 2. Planos de La Paya (tomados de Ambrosetti 1907) y de El Churcal (tomado de Raffino 1984).

23 Estudios ATACAMEÑos

Arqueología y Antropología Surandinas 
Dentro de la misma expedición, se efectuaron excavaciones en Kipón, un sitio integrado por un conjunto de recintos de muros de piedra muy deteriorados, emplazado a unos $15 \mathrm{~km}$ al norte de La Paya. Siguiendo los mismo a criterios que Ambrosetti aplicó para La Paya, Debenedetti (1908) describe 13 tumbas tipo cista, tres de las cuales contenían pucos negros pulidos.

Dillenuis (1909), al tratar una colección de pucos procedente de la localidad de La Poma, hacia el extremo norte del valle Calchaquí, también describe pucos de superficies negras pulidas, aunque no todos ellos corresponden al mismo período. Según las ilustraciones (Dillenius 1909: figs. 3, 4 y 7) la morfología de algunos pucos negros es la de la alfarería negra pulida, propia de los sitios del período Formativo del valle Calchaquí, que se asemeja a la del tipo San Pedro Negro Pulido del Salar de Atacama (Tarragó 1980, 1996; Baldini 2007). ${ }^{4}$ Con esto podría relacionarse la diferencia que la autora percibe en la calidad de las piezas:

"Los pucos negros en general son pucos convexos de pasta fina, de arcillas grises, como puede reconocerse en las líneas de fractura, muy bien trabajados, livianos, de paredes delgadas elegantes y completamente pulidos de negro conservando algunos cierto brillo metálico. Pero hay también pucos toscos, de arcillas pesadas y si bien negros, no lustrosos" (Dillenuis 1909: 2324; fig. 3).

Bennett y colaboradores (1948) analizan los contextos de 79 tumbas de La Paya, discriminando un grupo inca, otro transicional y un tercero más antiguo, o calchaquí, que reflejan cambios en el tiempo y contactos externos durante la ocupación del sitio. Mencionan pucos negros pulidos para los tres grupos de tumbas y destacan que en el grupo más antiguo los pucos negros son los más comunes, pero no resultan distintivos del mismo (Bennett et al. 1948: 74). Por su parte, Serrano $(1958,1963)$

3 En Kipón se efectuó un total de 50 excavaciones, con hallazgo de tumbas sin paredes de piedra, o bien, sin resultados.

4 Por ejemplo, piezas 2469 de la Figura 3 y 2414 de la Figura 4 en Dillenius (1909). Cabe señalar que los pucos del período Formativo presentan distintas variantes: hay de cuerpo elipsoide u ovoide y más profundo y con bordes evertidos, engrosa dos en la cara externa; otros son más abiertos, con bordes levemente evertidos y también con labios engrosados. Poseen pequeñas asas mamelonares debajo del borde y bases indiferenciadas a la vista (Baldini 2007: fig. 5). describe la cerámica más frecuente del mismo sitio y la denomina La Paya dibujos negros. También menciona un tipo La Paya Negro Pulido, pero haciendo referencia a las piezas halladas en la quebrada de La Paya de La Poma correspondientes al tipo San Pedro Negro Pulido y procedentes de San Pedro de Atacama.

Con posterioridad se reconocieron en el valle nuevas variantes decoradas tardías, como Las Pailas (Tarragó 1975, 1980; Tarragó y De Lorenzi, 1976) y Molinos (Baldini 1992a, 1992 b, 1996-97), diferentes de la santamariana y situadas cronológicamente a partir de los siglos IX-X, a la par que se explicitaba la necesidad de encarar un análisis sistemático de la alfarería de los Desarrollos Regionales del valle Calchaquí, y de su especificidad dentro del amplio espectro de la tradición santamariana (Baldini 1980; Tarragó 1980) (Figuras 4 y 5). ${ }^{5}$

5 La alfarería de Las Pailas consiste en pucos de pasta compacta y asas mamelonares decorados externamente con bandas de líneas verticales o entrecruzadas en negro sobre rojo, alternando en algunos casos el baño de fondo con el color natural de la superficie. Además, se asocian a piezas con aplicaciones al pastillaje que les dan aspecto ornitomorfo. La de Molinos presenta cuencos, cántaros, ollas y platos pintados con un reducido número de motivos geométricos, predominando series verticales de bandas de líneas rectas y onduladas, pintados en negro sobre un fondo blanquecino, que puede alternar con otro de color rojo, o el fondo natural de la superficie (Tarragó 1980; Baldini 1992b, 1996-97). Por su parte, la alfarería santamariana está integrada por variedad de ollas, cuencos y urnas para el entierro de infantes con decoración estandarizada y con fuerte simbolismo. Las urnas tienen un cuerpo a veces segmentado en dos partes, con asas cinta dispuestas simétricamente, y un cuello subcilíndrico que se abre hacia la boca. En la decoración, pintada en negro o en negro y rojo sobre fondo crema, a veces combinada con diseños al pastillaje, se destaca una representación antropomorfa, una cara en el cuello de la pieza, conformada por cejas, ojos, y boca que definen mejillas con profusión de motivos geométricos y zoomorfos. El resto de la representación humana, plasmada en el cuerpo de la vasija, se limita a la indicación de brazos curvos pintados y/o en relieve, que se asocian también a figuras zoomorfas y geométricas. Similares motivos poseen los cuencos de forma generalmente convexa que comúnmente sirvieron de tapas de las urnas; en algunos casos presentan un borde evertido. Esta alfarería cubre un extenso rango temporal, desde comienzos del primer milenio de la era hasta el contacto hispano-indígena, a través del cual se producen modificaciones en el estilo. Otras variantes estilísticas son regionales, ya que la cerámica santamariana se distribuye por amplios sectores de las provincias de Salta, Catamarca y Tucumán. 


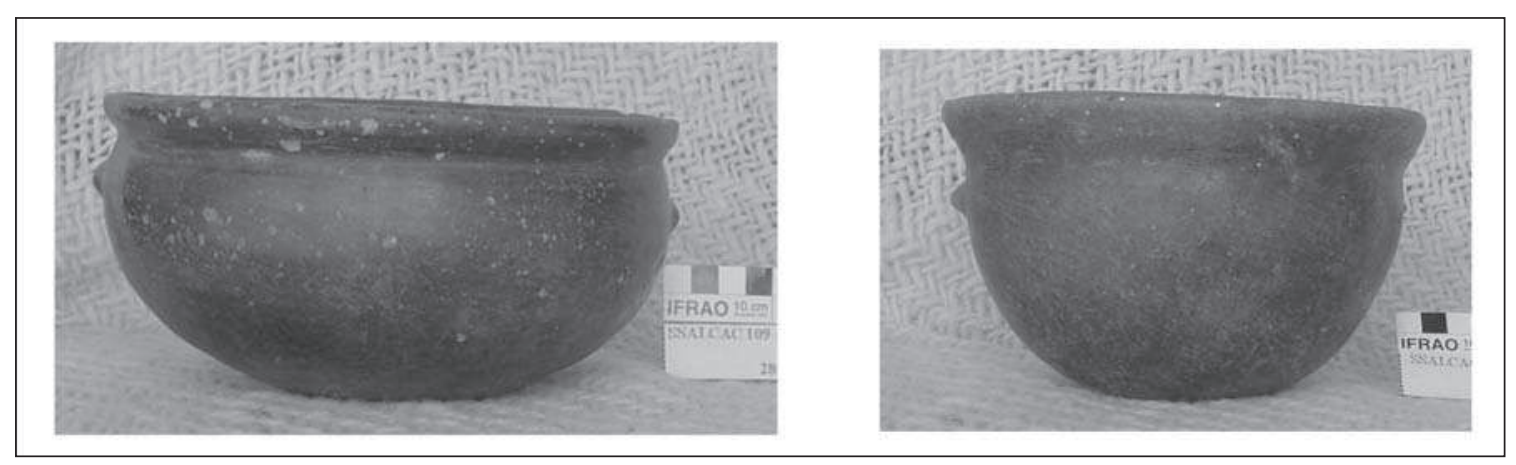

Figura 3. Vasijas no restringidas.

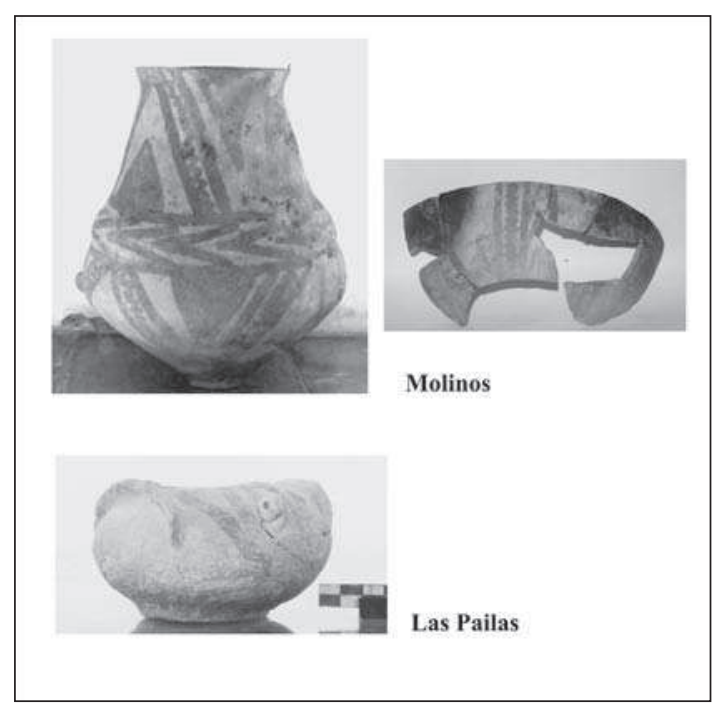

Figura 4. Vasijas restringidas.

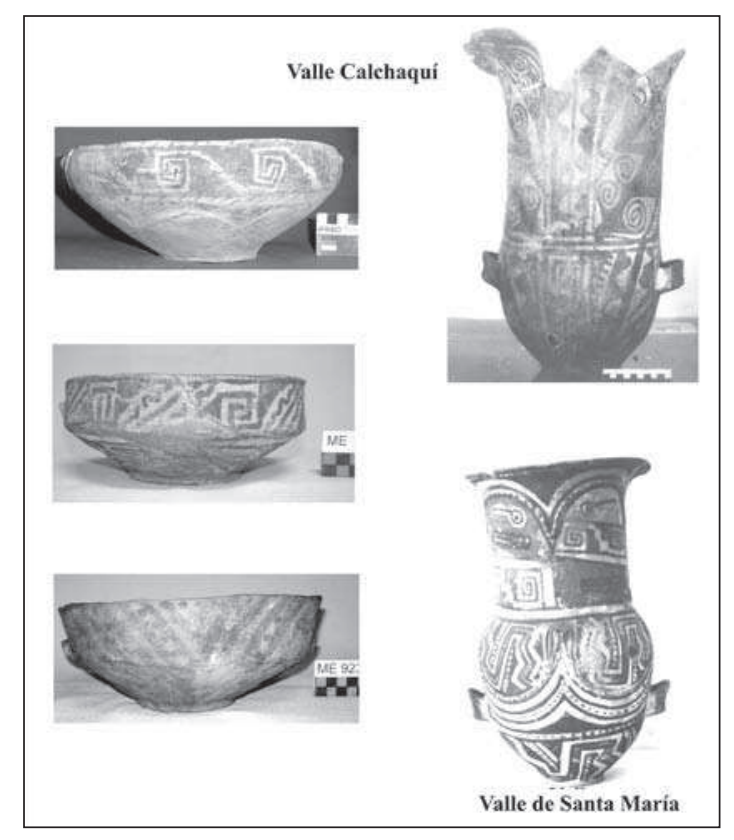

Figura 5. Alfarería santamariana.

estudio delineó las probables relaciones de la alfarería santamariana con el valle de Lerma y la Quebrada del Toro, y analizó los estilos cerámicos incaicos presentes en La Paya. Posteriormente, fueron abordadas las vinculaciones entre la cerámica de los Desarrollos Regionales iniciales (siglos IX a XI) con la de tradición santamariana-calchaquí ligeramente posterior (Baldini y Balbarrey 2004).

A diferencia de las alfarerías decoradas, la atención dada a la alfarería negra pulida de sitios de los Desarrollos Regionales, es limitada. En los trabajos que la mencionan, se explicitan las formas de las vasijas y se hacen comen- 
tarios referidos a su producción, destacando siempre la diferencia de la pasta y el tratamiento superficial con aquellos de la alfarería de tradición santamariana-calchaquí.

Ambrosetti (1907) incluye a los vasos y pucos negros en el acápite sobre "Alfarería de uso común". Los primeros son descritos como globulares, con boca grande, base pequeña, asas gruesas horizontales, y de variación notable en sus proporciones. A ellos se suman vasos más bajos y de bordes salientes de boca ancha. Entre los pucos distingue una forma convexa con un borde que se cierra hacia el interior y otra en la que las paredes se hacen verticales a partir del diámetro máximo. En suma, describe dos variantes de vasos y dos formas de pucos.

Mayor variedad de formas se advierte en el análisis de la cerámica de La Paya efectuado por Tarragó y De Lorenzi (1976), quienes distinguen platos muy abiertos con asa labio-adherida, pucos hemisféricos con un asa vertical similares a la tazas de la vajilla moderna, pucos restringidos y de contorno muy convexo, algunos con base diferenciada del cuerpo, pucos con un sector superior vertical y boca sin constreñir, y ollas globulares con bordes muy evertidos y asas cinta horizontales.

Por su parte, Calderari al analizar los estilos cerámicos incaicos de La Paya, describe el estilo La Paya Negro Pulido distinguiendo 10 formas de vasijas, entre ellas cuatro formas de escudillas y tazones, frascos, ollas y ollitas de pie y botellas de asa lateral; éstas dos últimas, junto a una forma de escudilla con asa botón, corresponden a formas propias de la cerámica inca (Calderari 1991a: 156).

Respecto de la alfarería del sitio El Churcal, Raffino (1984; Raffino et al.1976) expresa que la de tipo El Churcal Negro Pulido, en todo similar a las vasijas de La Paya, presenta una única forma, la de puco hemisférico de contorno simple, de paredes delgadas, manufacturado con una pasta homogénea y bien cocida, y cuyo diámetro oscila entre los 90 y $250 \mathrm{~mm}$. Referencias adicionales sobre la presencia de vasijas negras pulidas en contextos similares a los anteriores son proporcionadas por Tarragó y colaboradores (1979) para el sitio Tero de Cachi, por Pollard (1983) para el sitio Borgatta de Cachi Adentro, por Alfaro de Lanzone (1985) para recintos de La Paya, y por Baffi y colaboradores (2001) para un entierro en urna en Ruiz de Los Llanos. Finalmente, DeMarrais (1997) y Gifford (2003) mencionan la presencia de restos de alfarería negra pulida en sitios tardíos del sector septentrional del valle.

En este contexto, analizamos piezas negras pulidas completas de sitios arqueológicos tardíos del valle Calchaquí, considerando sus atributos de forma y dimensiones, a fin de identificar la variabilidad que presenta esta alfarería, así como controlar su cronología, indicios de su similitud con vasijas similares de otras regiones y qué proporciones alcanza en unas y otras. A partir de muestras de fragmentos de La Paya presentamos también otros aspectos de su proceso de producción.

\section{* La muestra}

La muestra se conforma por materiales provenientes de los sitios La Paya y El Churcal, a los que tuvimos distintos niveles de acceso.

La colección de La Paya se formó por las compras realizadas por Ambrosetti y Boman, por posteriores expediciones dirigidas por Ambrosetti en 1906 y 1907 , que mediante múltiples excavaciones exhumó numerosas estructuras funerarias, así como de otro tipo de contextos de hallazgo, principalmente ollas y urnas depositadas directamente en la tierra, recuperándose más de 1500 piezas ingresadas al Museo Etnográfico J. B. Ambrosetti (ME), de donde aproximadamente $20 \%$ fue derivada a otros museos. Durante nuestro registro de la colección La Paya, 36.7\% de los materiales no pudo ser localizado. De acuerdo a Ambrosetti (1907), en los 203 sepulcros y hallazgos de La Paya se registró un número mínimo de 737 piezas cerámicas. ${ }^{6}$ Entre ellas se cuenta un número mínimo de 173 pucos y siete vasos negros pulidos, que provienen de 101 tumbas o hallazgos.?

6 Ambrosetti (1907) denomina "sepulcros" a las tumbas en cista de paredes de piedra, y "hallazgos" a los entierros en urnas directamente en tierra, $\mathrm{u}$ a otros rasgos que no contienen inhumaciones.

7 Nos referimos a un número mínimo dado que en algunos casos sólo se menciona el hallazgo de restos de pucos, sin dar detalles con los cuales diferenciar distintas piezas. En estos casos consideramos un número mínimo de 1. 
La muestra que analizamos proviene, principalmente, de las colecciones depositadas en el ME, el Museo E. Casanova de Tilcara (MEC), el American Museum of Natural History (Nueva York), el National Museum of American Indian y el National Museum of Natural History (Washington D.C.). Su registro directo y análisis permitió obtener información de 248 piezas de cerámica procedentes de tumbas/hallazgos de La Paya entre las cuales se registraron 61 de alfarería negra pulida. Estas comprenden 54 escudillas y escudillas hondas (los pucos negros de Ambrosetti) y otras siete piezas, dentro de las cuales identificamos tres ollas (los vasos negros de Ambrosetti) y cuatro piezas únicas: una ollita con asas, una escudilla con cuello alto, un plato hondo y una botella. ${ }^{8}$ Por su parte, de Casa Morada proceden 60 piezas que incluyen seis negras pulidas, de las cuales dos pudieron ser registradas de manera directa. A estos materiales de la colección de La Paya se suman otras vasijas negras pulidas del mismo sitio, detectadas en otros museos. Estas son, siete escudillas hondas y dos ollas obtenidas en una de las mencionadas expediciones de la Facultad de Filosofía y Letras, pero sin mayores datos sobre su contexto específico de hallazgo.

En suma, disponemos de un registro directo de 61 piezas de alfarería negra pulida de tumbas o hallazgos, dos de Casa Morada y otras nueve sin indicación exacta al interior del asentamiento, además de tres piezas casi completas que proceden de uno de los dos sondeos realizados en La Paya (Baldini 1981 Ms-a), lo que suma un total de 75 piezas de La Paya (Tabla 1).
En segundo lugar, la colección de El Churcal es producto de las excavaciones realizadas por Raffino (1984; Raffino et al. 1976) durante las décadas de 1960 y 1970 en ese sitio. El Churcal se emplaza en el margen occidental del valle Calchaquí, aproximadamente a $8 \mathrm{~km}$ al noreste de la actual población de Molinos (ver Figuras 1 y 2). Es un poblado con más de 500 recintos de muros de piedra aglutinados y dispuestos en dos sectores separados por un espacio público de grandes dimensiones y parcialmente delimitado por paredes. Los sectores con viviendas, sobre todo en la parte más baja de la terraza, están surcados por vías de movilidad, en las cuales se han registrado entierros de adultos en cistas así como de infantes en urnas. Fueron excavados recintos habitacionales, tumbas, entierros en urnas y se realizaron sondeos en distintos espacios sin construcciones, de lo cual resultó la colección de materiales, entre los que se obtuvieron 86 vasijas completas, y otras 35 fragmentadas (Raffino $1978 \mathrm{Ms}$ ). Entre las primeras se incluyen 14 piezas del tipo El Churcal negro pulido, que, en todos los casos se trata de pucos, hallados exclusivamente al interior de las 20 cistas excavadas, algunas de las cuales habían sido previamente saqueadas (Raffino 1984).

La alfarería de El Churcal se analizó principalmente a partir de las descripciones publicadas y en registros de excavación, motivo por el cual su tratamiento fue menos preciso que en el caso de La Paya. Las descripciones de las piezas en registros inéditos (Raffino $1978 \mathrm{Ms}$ ) nos permiten ahondar en la variabilidad morfológica de esos pucos. La mayoría es de paredes cur-

\begin{tabular}{|l|c|c|c|c|c|}
\hline \multirow{2}{*}{ Colección } & \multirow{2}{*}{$\mathbf{N}^{\mathbf{*}}$ vasijas } & \multicolumn{2}{|c|}{ Vasijas NP } & \multicolumn{2}{c|}{ Vasijas NP analizadas } \\
\cline { 3 - 6 } & & $\mathbf{n}^{\mathbf{0}}$ & $\%$ & $\mathbf{n}^{\mathbf{0}}$ & $\%$ \\
\hline La Paya & 797 & 186 & 23.33 & 63 & 33.8 \\
\hline El Churcal & 121 & 14 & 11.0 & 4 & 28.5 \\
\hline Total & 918 & 200 & & 67 & \\
\hline
\end{tabular}

Tabla 1. Total de vasijas y proporción de piezas negras pulidas (NP).

\footnotetext{
8 Al referirnos a estas categorías consideramos su definición según las proporciones de la vasija.
} 
vas y boca de menor diámetro que el diámetro máximo, uno posee borde evertido y asas, y un tercero podría ser de paredes rectas. Al igual que los de La Paya tienen bases planas o cóncavo-convexas, labios planos o convexos y, salvo un puco de borde evertido -identificado como olla en los registros-, carecen de asas. En la revisión de una parte importante de la colección en la localidad de Molinos, hallamos solo cuatro pucos negros pulidos, ninguno de los cuales posee número de identificación.

\section{* Caracterización de la alfarería negra PULIDA TARDía DEL VALlE CALCHAQUí}

Si bien este estudio trata principalmente con piezas completas y se centra en la variedad de formas, también considera otros aspectos de la manufactura a partir de fragmentos de alfarería negra pulida hallados en sondeos realizados en espacios entre recintos de La Paya. Los mismos se registraron en toda la columna estratigráfica con proporciones de entre 2 y $17 \%$ (frente a una abrumadora mayoría de fragmentos ordinarios y de la tradición santamariana-calchaquí), correspondiendo los mayores porcentajes a los niveles de excavación donde se hallaron fragmentos de una misma pieza.

A partir de esta última muestra observamos las características de manufactura, considerando fondo de pasta e inclusiones, y a nivel de fragmentos, acabado de superficie, fractura, espesor, entre otros (Baldini $1981 \mathrm{Ms}-\mathrm{b}$ ). La pasta tiene una matriz de tono gris oscuro a negro, con inclusiones escasas y pequeñas ( 0.06 a $0.25 \mathrm{~mm}$ ) de litoclastos grises, negros y rojos, y aisladamente pequeñas láminas de mica y granos de cuarzo, generalmente redondeados, distribuidos irregularmente. Se observan cavidades redondeadas e irregulares de 0.5 y $1 \mathrm{~mm}$. La textura es porosa, en algunos casos tendiendo a laminar, y la fractura es irregular, aunque en cierta proporción es recta. La superficie externa es de color gris oscuro (2.5 YR 3/o, 10 YR 3/1, 10 YR 4/1, de acuerdo a la Munsell Soil Color Chart 1975), en menor proporción definidamente negra (7.5 YR 2.5/0) pudiendo presentar sectores con tonalidades que tienden al pardo (2.5Y 5/2). La superficie interna es similar, pero es más frecuente el color negro. Ambas superficies fueron pulidas, aunque más intensamente la interna. Las paredes de los fragmentos y de las piezas completas tienen espesores de entre 4 y $7 \mathrm{~mm}$. Los labios son planos o convexos y entre las bases predominan las planas indiferenciadas o biplanas y en menor proporción son cóncavo-convexas. Las asas son infrecuentes y se limitan a algunas pocas formas. Los pucos tienen alturas máximas que varían entre 42 y $78 \mathrm{~mm}$, y los diámetros en la boca entre 100 a $190 \mathrm{~mm}$. En las vasijas restringidas el diámetro máximo oscila entre 100 y $187 \mathrm{~mm}$, y las bases entre 49 y $100 \mathrm{~mm}$.

Respecto de la forma de las vasijas, como mencionamos, algunos autores ya habían avanzado descripciones aplicando diferentes criterios. Por nuestra parte, efectuamos una clasificación considerando las normas propuestas por Shepard (1954) y Balfet y colaboradores (1983), a fin de caracterizar la totalidad de las piezas desde criterios homogéneos.

Trabajamos inicialmente con las vasijas que analizamos de modo directo en el ME, el MEC y en los mencionados museos de Nueva York y Washington D.C., registrando forma, dimensiones, variaciones de color y tratamiento de superficie, datos de procedencia y asociación, entre otros. Aplicando los criterios propuestos por Balfet y colaboradores (1983) para la determinación de categorías de vasijas, reconocimos cinco categorías generales: escudillas, ollas, cuencos, botellas y platos. Entre ellas, las escudillas resultan netamente mayoritarias, en tanto las otras están muy poco representadas. Para distinguir la variabilidad total del conjunto afinamos esa caracterización aplicando los criterios definidos por Shepard (1954), distinguiendo 10 formas específicas para esta muestra.

Entre las vasijas no restringidas hay escudillas, escudillas hondas, un plato y un plato hondo, que pueden presentar contornos simples o compuestos (Tabla 2 y Figura 6), en las que se distinguen las siguientes formas:

Forma A. Vasija no restringida, de contorno simple, sección de esfera.

Forma B. Vasija no restringida, de contorno simple, sección de ovaloide invertido.

Forma C. Vasija no restringida, de contorno simple, sección de cono invertido (un plato hondo con asa labio adherida vertical). 


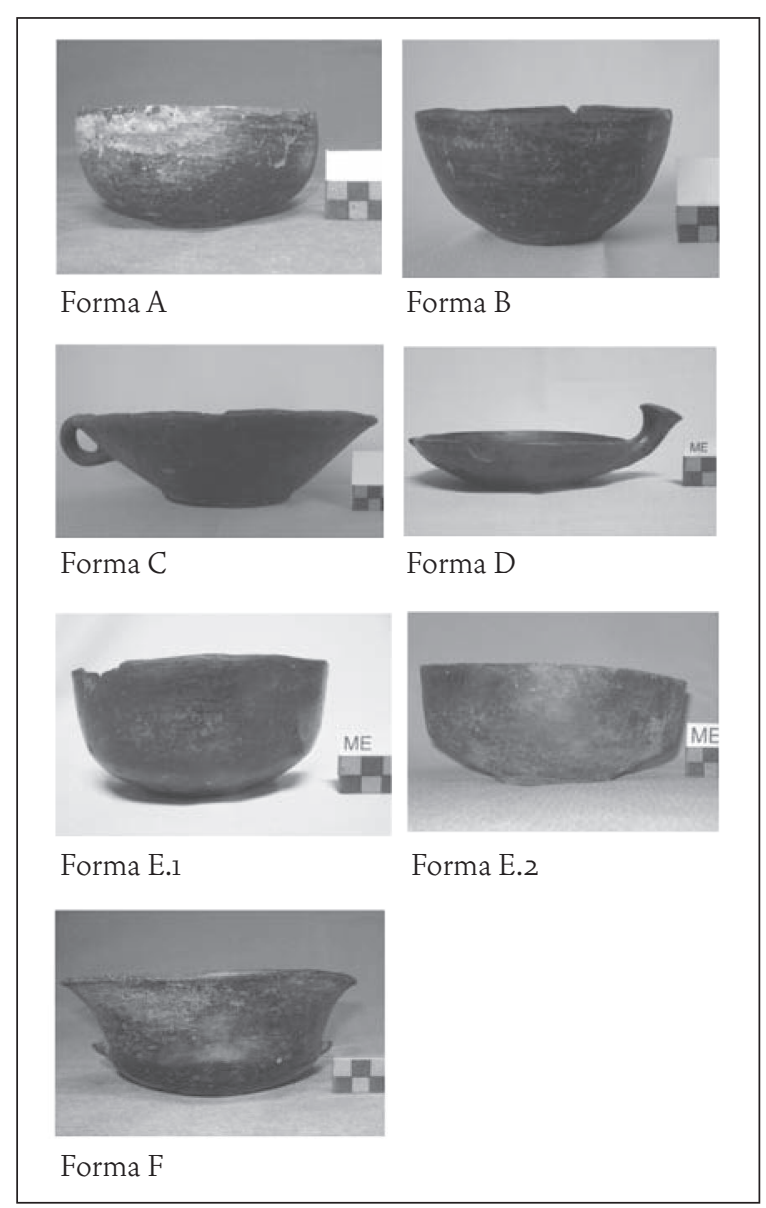

Figura 6. Vasijas no restringidas.

Forma D. Vasija no restringida, de contorno simple, sección de elipsoide horizontal (un plato pato con la cabeza reemplazada por un botón).

Forma E. Vasija no restringida, de contorno compuesto.? - El. Parte inferior sección de ovaloide y parte superior cilíndrica o que tiende levemente a cono invertido; - E2. Parte inferior sección de cono invertido y parte superior cilíndrica o que tiende levemente a cono invertido.

Forma F. Vasija no restringida, de contorno compuesto, parte inferior sección de elipsoide horizontal y parte superior sección de hiperboloide.

\footnotetext{
9 En esta forma se incluyen dos piezas incompletas procedentes de un sondeo realizado en La Paya.
}

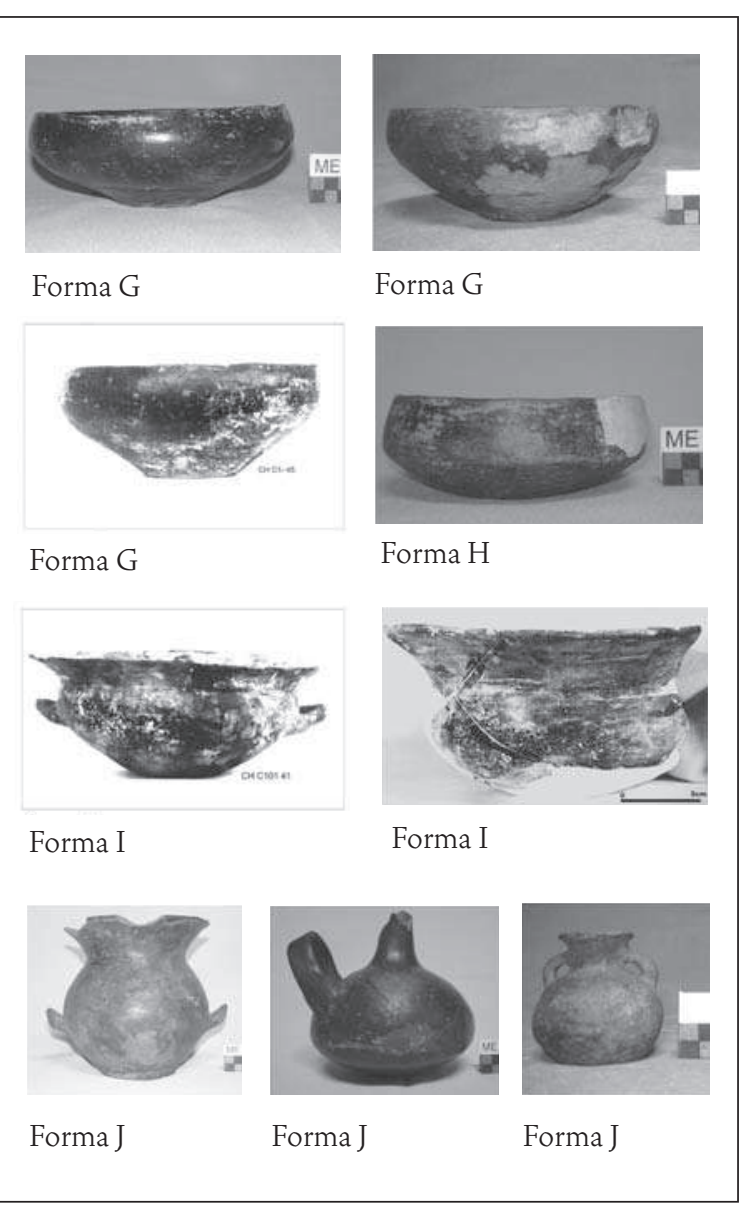

Figura 7. Vasijas restringidas.

Entre las vasijas restringidas, que pueden presentar contornos simples, compuestos o inflexionados, hay escudillas, escudillas hondas, ollas y botellas (Tabla 2 y Figura 7); se distinguen:

Forma G. Vasija restringida simple y dependiente, de contorno simple, sección de ovaloide invertido. Incluye una pequeña olla.

Forma G': Vasija restringida simple y dependiente, de contorno simple, sección de ovaloide invertido.

Las formas $G$ y $G$ ' se diferencian porque la primera tiene un cuerpo netamente ovaloide y con un punto de tangencia vertical (PTV) cercano al borde, la forma G' posee PTV más bajo, hacia la altura media de la pieza, que hace menos aparente su forma ovaloide, que en algunos casos se acerca a una forma elipsoide que puede presentar la base diferen- 


\begin{tabular}{|c|c|c|}
\hline Forma & $\begin{array}{c}\mathrm{N}^{\circ} \mathrm{de} \\
\text { ejemplares }\end{array}$ & $\begin{array}{c}\text { Categorías } \\
\text { (Balfet et al.1983) }\end{array}$ \\
\hline A & 3 & Escudillas hondas \\
\hline B & 3 & Escudilla honda \\
\hline $\mathrm{C}$ & 1 & Plato hondo \\
\hline $\mathrm{D}$ & 1 & Plato $^{*}$ \\
\hline E & 10 & $\begin{array}{c}\text { Escudillas y escudillas } \\
\text { hondas }\end{array}$ \\
\hline $\mathrm{F}$ & 1 & Escudilla \\
\hline G & 47 & $\begin{array}{l}\text { Escudillas, escudillas } \\
\text { hondas, una olla }\end{array}$ \\
\hline $\mathrm{H}$ & 1 & Escudilla honda y olla ${ }^{* *}$ \\
\hline I & 2 & Cuenco y olla \\
\hline $\mathrm{J}$ & 6 & Ollas y botellas \\
\hline
\end{tabular}

Tabla 2. Cantidad de ejemplares y categorías básicas en las formas A a la J. * Se trata de un plato pato. ** La olla presenta apéndices ornitomorfos.

ciada en el contorno. Sin embargo, la gradación continua de la forma de las vasijas y la relación entre la altura máxima y la altura del PTV no indican una diferenciación que justifique segmentarlas en dos formas diferentes.

Forma H. Vasija restringida simple y dependiente, de contorno compuesto, parte inferior sección de cono invertido y parte superior sección de cono. Incluye una pequeña olla con modelado zoomorfo.

Forma I. Vasija restringida simple y dependiente, de contorno simple, sección de ovaloide invertido, con borde/ cuello evertido y asas horizontales. ${ }^{10}$

Forma J. Vasija restringida independiente, de contorno inflexionado, cuerpo sección de ovaloide invertido, cuello hiperboloide. Esta forma incluye ollas y botellas. Estas últimas, si bien se encuadran en la misma categoría según los criterios de la definición de formas aplicados, se trata de piezas de diferente forma.

De acuerdo a lo anterior, la morfología de las escudillas presenta una gran variabilidad, y cabe destacar que su visión en conjunto produce una apariencia de mayor varie-

10 Los ejemplares que corresponden a la forma I son un gran fragmento del mencionado sondeo de La Paya y una pieza $(\mathrm{CH}$ C101-41) de El Churcal (Raffino 1978). dad todavía, debido - además de a la irregularidad propia de su manufactura que produce fuertes diferencias individuales-, a la diversidad de las dimensiones de las piezas. No obstante, en una primera aproximación a las dimensiones de las piezas de La Paya a través de la relación entre alturas y diámetros máximos, solo se destacan los platos y las vasijas con cuello, manteniendo cierta regularidad las proporciones de las escudillas, relación que se mantiene al incluir las piezas de El Churcal (Figuras 8 y 9).

La mayoría de las vasijas se incluye en dos formas, la $\mathrm{E}$ (cuencos de contorno compuesto) y la G (restringidas y de contornos simples; el tipo de cuenco conocido como "puco convexo" muy común en la alfarería de sitios tardíos del valle Calchaquí). En las demás formas solo se incluyen de una a cuatro piezas, como lo ejemplifica la forma F, similar a los pucos denominados campanuliformes ${ }^{11}$, aunque su parte superior es notablemente mayor que en aquellos, y en algunos casos se trata de vasijas de morfología incaica, como por ejemplo, la forma C.

Una vez definida la variedad de formas de la alfarería negra pulida desde las vasijas mismas, correlacionamos esas formas con las descripciones efectuadas por otros autores. Como se advierte en la Tabla 3, la muestra incluye mayor variabilidad de formas que las que ya habían sido señaladas. De las formas que definimos a partir de piezas de La Paya y El Churcal, dos no son identificables en las descripciones previas. Pero además, desde una visión preliminar de la colección del sitio Tero de los alrededores de Cachi (Tarragó et al. 1979) registramos otra forma novedosa de vasija: una escudilla honda con la que definimos la forma K:

Forma K: Vasija restringida simple dependiente, de contorno complejo, con un estrechamiento que separa una parte inferior sección de ovaloide de una parte superior sección de elipsoide (Figura 10).

En el Museo Arqueológico P. P. Díaz de Cachi (MAC) observamos otra vasija de este tipo procedente del sitio Viveros, emplazado a unos $4 \mathrm{~km}$ al oeste de Cachi (Tarragó y Díaz 1972).

Por otra parte, nuestra muestra no incluye la forma de

11 Pucos de contorno compuesto con una parte superior cóncava y evertida. 


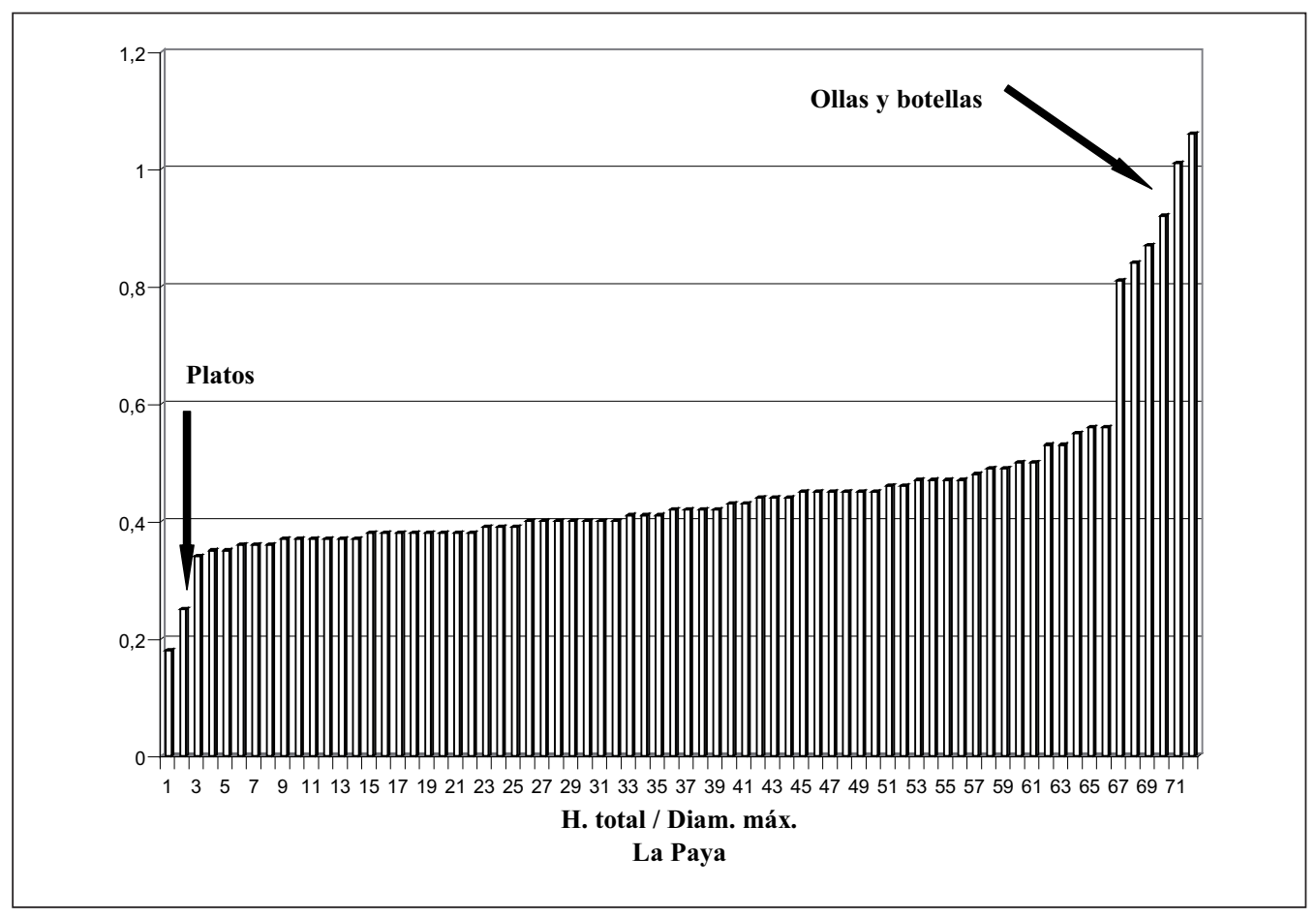

Figura 8. Proporciones de las vasijas de La Paya.

taza similar a las actuales (ver Figura 10), mencionada por Tarragó y De Lorenzi (1976: 20) que incluimos como forma L en la Tabla 3, y tampoco la olla con pie y asa lateral de morfología inca (forma $\mathrm{M}$ ), ni escudillas negras pulidas con asas mamelonares, correspondientes a las formas 8 y 2 , respectivamente, de Calderari (1991a). A la vez, aparentemente los pucos con cuerpo compuesto (forma E, y particularmente E2) no integran la muestra de Calderari (1991a: Cuadro 11), con lo que la variabilidad reconocida comprende un total de 13 formas para la cerámica negra pulida tardía del valle Calchaquí. ${ }^{12}$

Como se mencionó, las vasijas negras pulidas se asocian recurrentemente a la alfarería santamariana-calchaquí. En este sentido nos interesó verificar si las formas de la cerámica negra pulida son coincidentes con las de la alfarería de aquella tradición.

\footnotetext{
${ }^{12}$ La contrastación entre la definición de la forma 4 "escudillas y tazones de bordes rectos" y la ilustración correspondiente (Calderari 1991a: 156, Cuadro 11) no permiten aseverar la ausencia o presencia de la forma Eı. La ilustración sugiere que con "borde recto" se podría estar aludiendo a borde directo.
}

En su análisis estilístico de los pucos de tradición santamariana de La Paya, Calderari (1991b) definió siete formas, entre la cuales las formas 1, 4 y 6 son muy similares entre $s^{13}$, variando especialmente la altura del PTV en el contorno, y pueden adscribirse a nuestra forma $G$, así como los pucos denominados convexos por Ambrosetti: "El puco convexo o de paredes convexas se caracteriza por presentar, boca abajo, un cono truncado de poca altura y base muy ancha" (1907: 320). La pieza de cuello hiperboloide de nuestra forma $\mathrm{F}$ tiene solamente cierta similitud con los pucos con parte superior cóncava evertida del grupo Cachi (forma 7 de Calderari 1991b: lám. III), más conocidos como pucos campanuliformes, de los cuales se diferencia en la proporción de las alturas entre su parte inferior y la parte superior. Otras formas de pucos de tradición santamariana-calchaquí no se registraron en la muestra de vasijas negras pulidas. Es el caso de los cuencos con punto angular en el con-

\footnotetext{
13 "Forma 1: Pucos con cuello definido por un punto tangencial del contorno de borde convexo [...]. Forma 4: Pucos sin cuello de borde convexo [...]. Forma 6: Puco sin cuello de borde convexo" (Calderari 1991b: 4-5).
} 


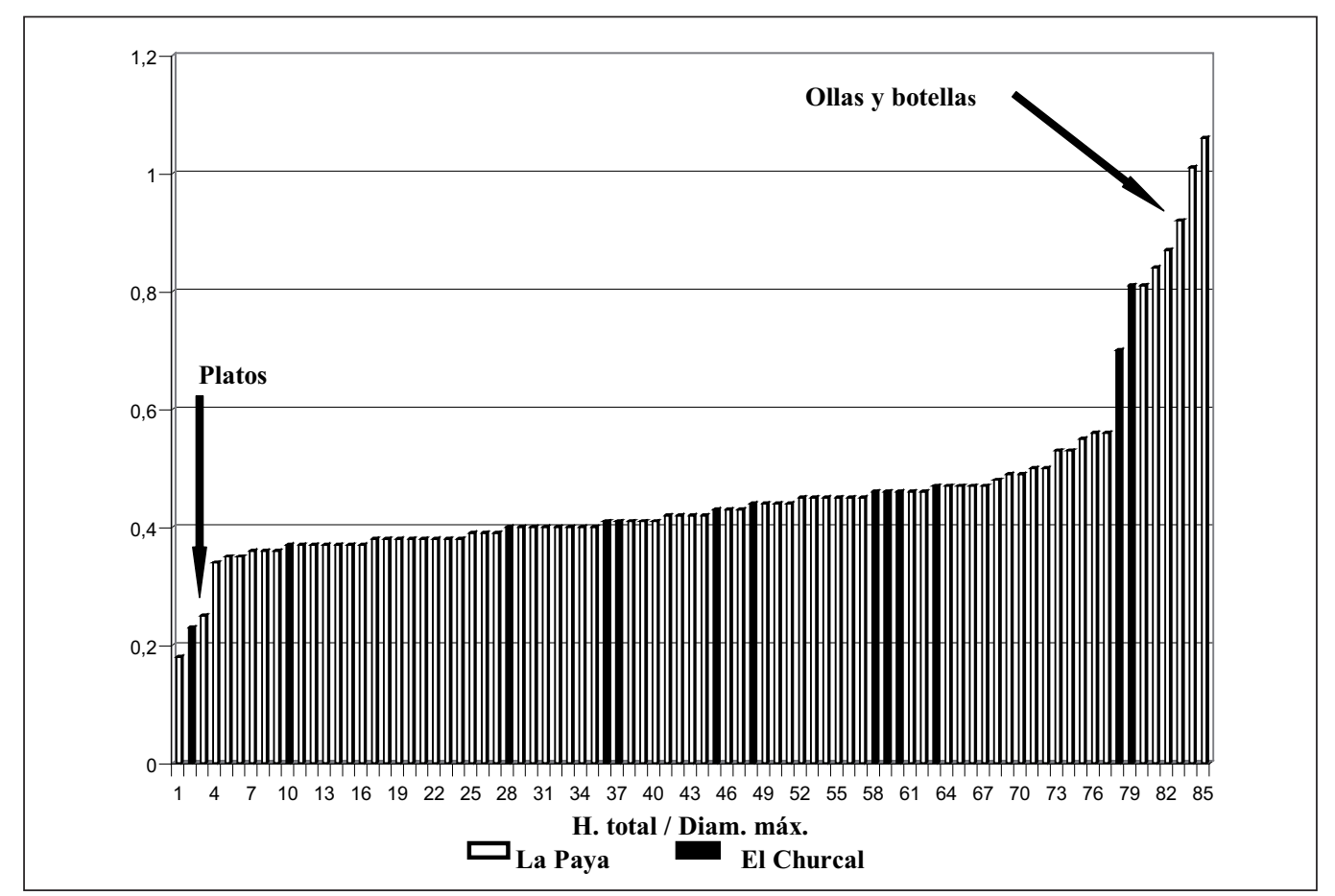

Figura 9. Proporciones de las vasijas de La Paya y El Churcal.

torno que define una parte superior cóncava o cóncava entranteylos pucos con borde modificado, formas 2 y 3 del grupo Calchaquí y 5 del grupo Cachi de Calderari (1991b: lám. III). En suma, si nos atenemos a esta comparación se aprecia cierta diferencia entre las formas de los pucos de aquella tradición cerámica y los de superficie negra pulida, que solo compartirían las formas de los comunes pucos convexos. Esto resulta consistente con la idea de una coexistencia de dos producciones alfareras diferentes en el valle Calchaquí, que se desprende de las diferencias de pasta, cocción en atmósfera reductora y tratamiento de superficie que la alfarería negra pulida tiene con respecto a la pintada (Dillenius 1909; Tarragó y De Lorenzi 1976; Raffino 1984; Calderari 1991a), diferencia que corroboramos con la muestra de vasijas negras pulidas de La Paya, que no se incluyen en los estándares de pasta definidos con fragmentos de tipo santamariano-calchaquí y molinos (Baldini y Balbarrey 2004).14 Sin embargo, hay que mencionar que las ollas negras pulidas de la forma J, son del tipo de las que Ambrosetti (1907) denomina vasos de boca ancha.

${ }^{14}$ Se encuentran en estudio cortes delgados de estos tipos de fragmentos.

\section{* Otras consideraciones sobre la CERÁMICA NEGRA PULIDA TARDÍA}

Además de caracterizar sistemáticamente todo el material accesible, nos interesó deslindar otros aspectos, como el lapso cronológico en el que se manufacturó esta cerámica, definir el espacio en que se registra, y su presencia o vinculación en o con sitios de otras regiones.

Según la información actual, esta cerámica negra pulida está presente en sitios tardíos emplazados entre Molinos y Payogasta en el sector central del valle Calchaquí (El Churcal, La Paya, Tero, Kipón, etc.) y hacia su extremo norte, como lo evidencia una parte del material de La Poma analizado por Dillenius (1909) y menciones sobre la presencia de alfarería negra pulida, aunque sin mayores especificaciones, en contextos tardíos de algunos sitios emplazados desde Cachi hasta La Poma (DeMarrais 1997; Gifford 2003). Aunque hacia el sur de Molinos la información arqueológica es muy reducida, aparentemente no hay menciones sobre el hallazgo de esta alfarería. 


\begin{tabular}{|c|c|c|c|c|c|c|c|}
\hline \multicolumn{7}{|c|}{ Vasijas negras pulidas } & $\begin{array}{c}\text { Pucos Santa María- } \\
\text { Calchaquí }\end{array}$ \\
\hline \multirow[b]{2}{*}{ Forma } & \multicolumn{3}{|c|}{ La Paya } & \multirow{2}{*}{$\begin{array}{c}\text { El Churcal } \\
\text { Raffino } \\
(1984)\end{array}$} & \multirow[b]{2}{*}{$\begin{array}{l}\text { Tero } \\
\text { MAC }\end{array}$} & \multirow{2}{*}{$\begin{array}{c}\text { Tastil } \\
\text { Cigliano } \\
(1973)\end{array}$} & La Paya \\
\hline & $\begin{array}{c}\text { Ambrosetti } \\
(1907)\end{array}$ & $\begin{array}{c}\text { Tarragó y De } \\
\text { Lorenzi (1976) }\end{array}$ & $\begin{array}{l}\text { Calderari } \\
\text { (1991b) }\end{array}$ & & & & Calderari (1991a) \\
\hline $\mathrm{A}$ & & & & & $X$ & & \\
\hline B & & & $\mathrm{X}$ & & & & \\
\hline C & & $X$ & $X$ & & & & \\
\hline $\mathrm{D}$ & & & $X$ & & & & \\
\hline E & X & $X$ & & & & $X ?$ & \\
\hline $\mathrm{F}$ & & $X$ & $X$ & & & & \\
\hline G & X & X & X & X & X & $\mathrm{X}$ & 1,4 y 6 \\
\hline \multicolumn{8}{|l|}{$\mathrm{H}$} \\
\hline I & & & & $X$ & & $X$ ? & \\
\hline $\mathrm{J}$ & X & X & $X$ & & & & \\
\hline $\mathrm{K}$ & & & & & $X$ & & \\
\hline $\mathrm{L}$ & & $X$ & & & & & \\
\hline \multirow[t]{3}{*}{$\mathrm{M}$} & & & X & & & & \\
\hline & & & & & & "Ollitas" & \\
\hline & & & & & & & $2,3,5$ \\
\hline
\end{tabular}

Tabla 3. Correlación de formas con las descripciones efectuadas por otros autores.

Con relación al lapso temporal en que se manufacturó esta cerámica negra pulida en el valle Calchaquí, los contextos en que se presenta corresponden fundamentalmente al período de Desarrollos Regionales, como lo evidencian las tumbas de La Paya, El Churcal y otros sitios cercanos. Por otra parte, fragmentos de vasijas negras pulidas se asocian a fechados de $830 \pm 95$ y $620 \pm 100 \mathrm{AP}$ en los niveles más profundos de los sondeos realizados en La Paya (Baldini 1980), de 740 \pm 50 AP para una tumba de El Churcal (Raffino 1984), a un rango de fechados entre $660 \pm 80$ y $855 \pm 80 \mathrm{AP}$ en un sondeo en el sitio Borgatta de Cachi Adentro (Pollard 1983) y $540 \pm 90 \mathrm{AP}$ en Ruiz de Los Llanos (Baffi et al. 2001 ), en todos estos casos sin asociación a materiales de época inca.

Algunos hallazgos indican que esta cerámica se producía desde inicios de los Desarrollos Regionales. El acompañamiento de un entierro del sitio Las Pailas de Cachi Adentro, diferente a aquellas más comunes cistas tardías, incluía "un puco grande Negro/ Rojo con posible filiación con el Shiquimil Geométrico, una ollita negra pulida", entre otros objetos (Tarragó 1980: 51; el subrayado es nuestro). La posible filiación de la vasija negro sobre rojo sugiere que podría asimilarse a la alfarería del sitio Molinos I (Baldini 1996-97), con fechados entre 870 \pm 90 AP y $1010 \pm 50$ AP (Baldini y Balbarrey 2004), es decir, entre los siglos IX y XI. ${ }^{15}$ Además, un entierro directo de adulto vinculado a este asentamiento que incluía una vasija, también con la decoración geométrica en negro sobre rojo común en Molinos I, fue fechado en $640 \pm 60$ AP (Baldini y Baffi 2008), fecha que resulta algo más moderna que otras del sitio, pero coincide con un fechado sobre carbón del piso de uno de sus recintos (LP-1631: 650 $060 \mathrm{AP}$ ). En síntesis, los fechados y los contextos apuntan a que esta alfarería negra pulida está presente ya en momentos tempranos de los Desarrollos Regionales.

Ambrosetti (1907) manifiesta que en La Paya no se encuentran vasijas negras pulidas en los contextos mortuorios que contienen los objetos que identifica como exóticos, los que corresponden básicamente a objetos incaicos, sugiriendo que las piezas negras pulidas no perdurarían más allá del período de Desarrollos Regionales. Sin embargo, la revisión del conjunto de la documentación y materiales de La Paya, permite afirmar que en varias de las tumbas se asocian a objetos incaicos; por ejemplo, el sepulcro 116 con dos pucos negros asociados, entre otros objetos, a un plato pato, una valva de molusco del género Pecten y un tumi (Ambrosetti 1907: 201-

\footnotetext{
15 En este sitio se hallaron asociados a la cerámica Molinos dos tiestos negros pulidos en un sondeo, y un tercero en otro sondeo (Baldini 1992a).
} 


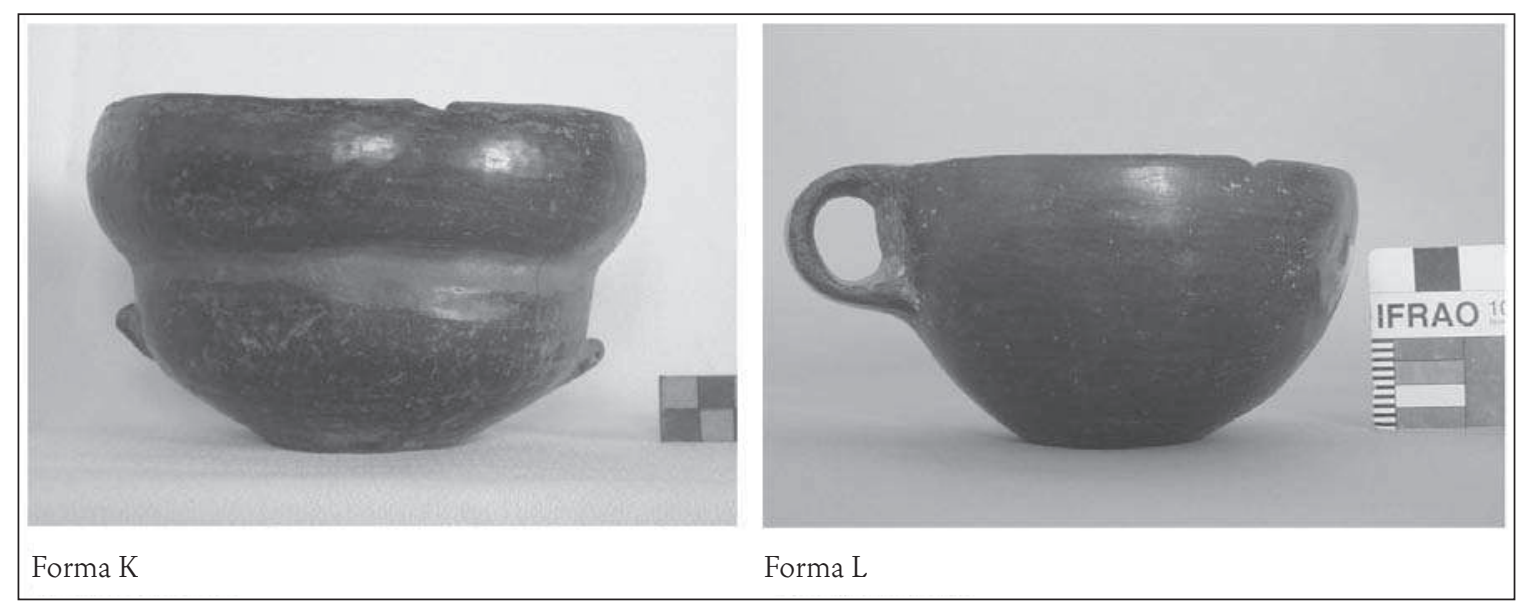

Figura 10. Formas K y L.

205), o el sepulcro 128 con tres pucos negros, un plato pato y otro con asa ojal, un aribaloide y otros materiales locales (Ambrosetti 1907: 211-214). Del mismo modo, en excavaciones en el recinto 4 de La Paya, adyacente al que contiene a Casa Morada, se ha registrado un puco negro pulido tapando una olla con pie de morfología inca (Alfaro de Lanzone 1985: 574). Estas asociaciones señalan en forma elocuente la persistencia de las piezas negras pulidas del período de Desarrollos Regionales hasta épocas más recientes.

También el hallazgo de vasijas negras pulidas de morfología inca apunta en igual sentido, aunque no necesariamente obedezcan a alfareros locales produciendo vasijas de forma inca.

Otro aspecto interesante respecto de esta cerámica es la existencia de alfarerías similares en regiones aledañas. Fuera del valle Calchaquí, en sitios tardíos de la Quebrada del Toro, como Tastil, Morohuasi y Puerta de Tastil, también se registra un tipo de alfarería negra pulida. Boman (1908) menciona este tipo de cerámica para Puerta de Tastil y Morohuasi, y sondeos realizados en basureros de este último sitio también proporcionaron fragmentos de cerámica negra pulida con proporciones de 5 a 15\% por capa (Raffino 1972). En Tastil (Cigliano 1973) la cerámica negra pulida alcanza a $7 \%$ de las vasijas, proporción menor que en los sitios del valle Calchaquí, donde llega a $24.42 \%$ del total de vasijas de La Paya, considerando las procedentes de los entierros y las de Casa Morada, en tanto que en El
Churcal alcanza a 11\%, en un número mucho menor de entierros (tabla 4).

El tratamiento más detenido para la alfarería negra pulida tardía de la Quebrada del Toro se realizó con los materiales de Tastil. Cigliano y Calandra (1973) describen el tipo Tastil Negro Pulido que incluye ollitas subglobulares y cuatro variedades de pucos:

- subglobulares y de paredes convexas que tienden a converger hacia el borde;

- de paredes rectas hacia el borde y quebradas hacia la base;

- de paredes divergentes;

- de paredes convexas que tienden a converger y un cuello evertido y asas horizontales.

Si bien no analizamos directamente las piezas de la Quebrada del Toro, de su descripción se desprende una interesante similitud con las de La Paya, como sus características generales, antiplástico fino, textura homogénea, fractura regular, bordes invertidos o evertidos, bases planas o convexas (Cigliano y Calandra 1973: 127-128, Figura 38) y la forma de algunas de las piezas, que admiten su inclusión dentro de las que definimos con el material de La Paya y El Churcal (Tabla 3), aunque habría menor variedad de formas. Estas similitudes coinciden en señalar vínculos entre las sociedades tardías del valle Calchaquí y de la Quebrada del Toro, ya destacados por varios autores para el sector norte del primero (Cigliano 1973; Tarragó y De Lorenzi 1976; Cremonte y Solís 1998; Gifford 2003, entre otros), nexos 


\begin{tabular}{|l|l|c|c|c|c|c|c|}
\hline \multirow{2}{*}{ Procedencia } & \multirow{2}{*}{ Entierros, vasijas y vasijas NP } & \multicolumn{2}{|c|}{ La Paya } & \multicolumn{2}{|c|}{ El Churcal } & \multicolumn{2}{|c|}{ Tastil } \\
\cline { 3 - 8 } & & $\mathbf{n}^{\mathbf{0}}$ & $\%$ & $\mathbf{n}^{\mathbf{0}}$ & $\%$ & $\mathbf{n}^{\mathbf{0}}$ & $\%$ \\
\hline Entierros y cistas & Entierros/cistas & 201 & & 43 & & $109^{*}$ & \\
\hline & Entierros con vasijas NP & 101 & 49.75 & 7 & 16 & 8 & 7.3 \\
\hline & Vasijas & 737 & & 125 & & 150 & \\
\hline & Vasijas NP & 180 & 24.42 & 14 & 11 & 11 & 7.3 \\
\hline Casa Morada & Vasijas & 60 & & & & & \\
\hline & Vasijas NP & 6 & 10 & & & & \\
\hline Sondeos & Vasijas & $6357^{* *}$ & & & & & \\
\hline & Vasijas NP & 347 & 5 & & & & \\
\hline
\end{tabular}

Tabla 4. Cantidad y proporciones de vasijas negras pulidas (NP) por sitio, según procedencia. * Se incluyen los hallazgos en dos recintos y un hallazgo de superficie. ${ }^{* *}$ En esta muestra se incluyen los fragmentos con los que se reconstruyeron las tres vasijas incompletas consideradas para el sitio.

que podrían extenderse a sociedades emplazadas algo más al sur en el valle Calchaquí.

En otras direcciones, Boman (1908) menciona una cerámica negra pulida y engobada con plombagina del valle de Lerma (Salta). Para la misma región Mulvany y colaboradores (2007) indican el hallazgo de fragmentos negros pulidos correspondientes a escudillas. Estos datos, aunque escasos, también podrían señalar vínculos extrarregionales de las sociedades calchaquíes.

\section{* Comentarios finales}

La recopilación de piezas de sitios del valle Calchaquí no deja duda sobre que la alfarería negra pulida es una variedad propia de yacimientos de los sectores medio y norte de este valle, que se asocia recurrentemente a la cerámica santamariana-calchaquí, y que alcanza proporciones significativas en los contextos mortuorios, de 24 y $11 \%$ del total de piezas de La Paya y de los enterratorios de El Churcal, respectivamente. Estos sitios poseen las muestras de vasijas más numerosas y son los que cuentan con mayor información. Desde la perspectiva temporal, se registra en sitios que abarcan todo el período de Desarrollos Regionales y la época inca, sin que se hayan observado modificaciones morfológicas en las piezas negras pulidas procedentes de contextos con materiales incaicos, salvo las pocas que reproducen formas incas.
En el conjunto de piezas negras pulidas consideradas se distinguen 13 formas, con una amplia mayoría de escudillas entre las que se da la mayor variabilidad, y en las que además se observan discrepancias entre algunas de sus formas y las de la alfarería santamariana-calchaquí.

Una perspectiva interesante que surge de la búsqueda de piezas semejantes en otros ámbitos, es la posibilidad de que esta alfarería pueda ser incluida entre los indicadores de vinculación entre las sociedades calchaquíes y las de regiones aledañas. Con relación a esto es necesario deslindar, a partir de mayor y mejor información, si ambas regiones comparten una tradición de manufactura específica o este tipo de alfarería circuló entre ambas regiones.

Finalmente, visto este conjunto de piezas surgen distintas interrogantes. En el valle Calchaquí, como en otros ámbitos del NOA, durante el período Formativo se producía una alfarería de superficies negras pulidas (Raffino 1977; Tarragó 1996; Baldini 2007, entre otros). La cerámica negra pulida tardía del valle Calchaquí, ies la continuación de una larga tradición de producción cerámica que se extiende desde aquel período hasta conformar una variedad particular en tiempos más recientes, más allá de las esperables diferencias de las formas y manufactura entre unas y otras? La distancia temporal es muy extensa y se desconocen las alfarerías comunes en la región durante la segunda mitad del primer milenio, por lo que esto solo podrá responderse al contar con mayores elementos a partir de estudios cerámicos en una escala de larga duración. 
¿Su aparente ausencia hacia el sector sur del valle obedece únicamente a problemas de registro o está reflejando el límite espacial de una producción alfarera específica? En el valle de Santa María existe otra cerámica negra pulida tardía, la Famabalasto Negro Grabado, que se diferencia de las del valle Calchaquí por poseer decoración geométrica incisa en sus bordes y por su variedad de formas (Cigliano 1958). La ausencia de esta cerámica en las colecciones de el valle Calchaquí, como las de la Paya, El Churcal y Tero, indica que en esta región no se produjo cerámica Famabalasto Negro Grabado. Su aparición en la misma, que solo incluye un puco de la Colección Zavaleta depositado en el ME con procedencia de la localidad de Cachi (la que no es firme por las condiciones de la colección) y su registro en Potrero de Payogasta (Palamarczuk y Manasiewicz 2001, cit. en González y Tarragó 2004), obedecería a procesos de circulación de materiales, particularmente durante la ocupación inca.
Es sugerente que en los valles Calchaquí y de Santa María las sociedades santamarianas produjeran vasijas negras pulidas de estilos diferentes. ¿Son estas dos alfarerías negras otra manifestación de las diferencias estilísticas que se observan en la amplia dispersión en el Noroeste Argentino de las sociedades productoras de alfarería santamariana, y que en el valle Calchaquí se expresan, por ejemplo, en la identificación de variaciones estilísticas entre las urnas y pucos santamarianos de uno y otro ámbito? (Tarragó y De Lorenzi 1976; Baldini 1981 Ms-a; Caviglia 1985 Ms; Calderari 1991b).

Agradecimientos A R. Raffino que nos proporcionó la información inédita sobre El Churcal, y a V. Palamarczuk, que aportó la información sobre el puco Famabalasto Negro Grabado de Cachi.

\section{* Referencias citadas}

ALFARO DE LANZONE, L., 1985. Investigación arqueológica de la "ciudad" prehistórica de La Paya. depto. Cachi, prov. de Salta, Argentina. Beitrage zur allgemeinene und Vergleichenden Archaeologie, Band 7:563-560. Sonderdruck, Bonn.

AMBROSETTI, J. B., 1902. El sepulcro de "La Paya" últimamente descubierto en los valles calchaquíes (provincia de Salta).Anales del Museo Nacional de Buenos Aires vol. 8 (Tercera Serie, tomo 1): 119-148.

1907. Exploraciones arqueológicas en la ciudad prehistórica de La Paya (valle Calchaquí, prov. de Salta). Publicaciones de la Sección Antropológica de la Facultad de Filosofía y Letras de la Universidad de Buenos Aires 3

BAFFI, E., L. BALDINI y R. PAPPALARDO, 2001. Entierro de un párvulo en urna. Ruiz de Los Llanos (valle Calchaquí, Salta, Argentina). Boletín del Museo de Arqueología y Antropología de la Universidad Nacional Mayor de San Marcos 4 (3): 69-75.

BALDINI, L., 1980. Dispersión y cronología de las urnas de tres cinturas en el Noroeste Argentino. Relaciones de la Sociedad Argentina de Antropología 14 (1): 49-61.

1981 Ms-a. Estudio comparativo de la cultura santamariana del valle Calchaquí respecto de la del valle de Santa María. Informe CONICET.
1981 Ms-b. Excavaciones en La Paya. Informe CONICET

1992a. El sitio Molinos I dentro de los esquemas de desarrollo cultural del Noroeste Argentino.Arqueología 2: 53-68.

1992b. La transición entre el Formativo Medio y los Desarrollos Regionales en el área valliserrana del NOA. Contribución Arqueológica 4: 26-35.

1996-97: Reflexiones sobre los procesos históricos del NOA. Ruptura/continuidad después de Aguada. Shincal 6:249-256.

2007. Cancha de Paleta, un cementerio del período Formativo en Cachi (valle Calchaquí, Salta). Cuadernos de la Facultad de Humanidades y Ciencias Sociales de la Universidad Nacional de Jujuy 32: $13-33$.

BALDINI, L. y E. BAFFI, 2008. Modos funerarios y alimentación. El caso de Molinos II, valle Calchaquí, Salta, Argentina. Actas del XII Congreso Latinoamericano de Religión y Etnicidad: Cambios Culturales, Conflictos y Transformaciones Religiosas. Bogotá, CD. ISBN 97094056-4-0.

BALDINI, L. y G. BALBARREY, 2004. Análisis de pastas cerámicas tardías del valle Calchaquí central (Salta, Argentina). Chungara 36, vol. especial 2: 1069-1080. 
BALFET, H., M. FAUVET-BERTHELOT y S. MONZON, 1983. Pour la normalization de la description des poteries. Editions du Centre $\mathrm{Na}$ tional de la Recherche Scientifique, París.

BENNETT, W., E. BLEILER y F. SOMMER, 1948. Northwest Argentine archaeology. Yale University Publication in Anthropology 38.

BOMAN, E., 1908. Antiquités de la région andine de la République Argentine et du désert d'Atacama. Imprimerie Nationale, París.

CALDERARI, M., 1991a. Estilos cerámicos incaicos de La Paya. $A c-$ tas del XI Congreso Nacional de Arqueología Chilena, vol. 2, pp. 151164. Santiago.

1991b. El concepto de estilo en ceramología: La tradición santamariana en los pucos de La Paya. En El arte rupestre en la arqueología contemporánea, M. Podestá, M. I. Hernández Llosas y S. Renard (Eds.), pp. 1-13. Edición de M. Podestá, Buenos Aires.

CAVIGLIA, S., 1985 Ms. Las urnas para niños del valle Yocavil y Calchaquí. Su reinterpretación sobre una base gestáltica.

CIGLIANO, E., 1958. Arqueología de la zona de Famabalasto. Revista del Museo de La Plata N.S., Sección Antropología V: 29-122.

(Ed.) 1973. Tastil. Una ciudad preincaica argentina. Ediciones Cabargón, Buenos Aires.

CIGLIANO E. y H. CALANDRA, 1973. Cerámica. En Tastil. Una ciudad preincaica argentina, E. Cigliano (Ed.), pp. 123-162. Ediciones Cabargón, Buenos Aires.

CREMONTE, M. B. y N. SOLÍS, 1998. La cerámica del Pucara de Volcán: Variaciones locales y evidencias de interacción. En Los desarrollos locales y sus territorios. Arqueología del NOA y sur de Bolivia, M. B. Cremonte (Ed.), pp. 155-196. Universidad Nacional de Jujuy, San Salvador de Jujuy.

DEBENEDETTI, S., 1908. Excursión arqueológica a las ruinas de Kipón (valle Calchaquí, provincia de Salta). Publicaciones de la Sección Antropológica de la Facultad de Filosofia y Letras de la Universidad de Buenos Aires 4.

DEMARRAIS, E., 1997. Materialization, ideology and power: The development of centralized authority among the pre-Hispanic polities of the valle Calchaquí, Argentina. Ph.D. Thesis. University of California, Los Angeles.

DILLENUIS, J., 1909. Observaciones arqueológicas sobre alfarería funeraria de la "Poma" (valle Calchaquí, provincia de Salta). Publicaciones de la Sección Antropológica de la Facultad de Filosofía y Letras de la Universidad de Buenos Aires 5.
GIFFORD, C. H., 2003. Local matters: Encountering the Imperial Inkas in the South Andes. Ph.D. Thesis. Columbia University, Nueva York.

GONZÁLEZ, A. R.y P. DÍAZ, 1992. Notas arqueológicas sobre “Casa Morada”, La Paya, provincia de Salta. Estudios de Arqueología 5: 9-64.

GONZÁLEZ, L. y M. TARRAGÓ, 2004. Producción tecnológica e identidad durante el dominio incaico en el Noroeste Argentino. Boletín de Arqueología PUCP 8:191-207.

MULVANY, E., E. M. MAMANI, F. VIVEROS y M. ILARI, 2007. Estilos incaicos del Horizonte Tardío en la región de Lerma. Pacarina vol. especial, núm. 1:499-505.

MUNSELL SOIL COLOR CHARTS, 1975. Munsell Color Macbeth A Division of Kollmorgen Corporation, Baltimore.

POLLARD, G., 1983. Nuevos aportes a la prehistoria del valle Calchaquí, Noroeste Argentino. Estudios de Arqueología 3 y 4: 71-92.

RAFFINO, R., 1972. Las sociedades agrícolas del período Tardío en la Quebrada del Toro y aledaños. Revista del Museo de La Plata N.S. Sección Antropología VII: 157-210.

1977. Las aldeas del Formativo Inferior de la Quebrada del Toro (Salta, Argentina). Estudios Atacameños 5: 64-108.

1978 Ms. Excavaciones en El Churcal. Museo de La Plata, La Plata.

1884. Excavaciones en El Churcal (valle Calchaquí, Argentina). Revista del Museo de La Plata, Antropología 7: 223-263.

RAFFINO, R., E. CIGLIANO y E. MANSUR, 1976. El Churcal. Un modelo de urbanización tardía en el valle Calchaquí. Revista del Museo de Historia Natural de San Rafael 3 (1):33-42.

SERRANO, A., 1958. Manual de cerámica indígena. Editorial Assandri, Córdoba.

1963. Líneas fundamentales de arqueología salteña. Edición del autor, Salta.

SHEPARD, A., 1954. Ceramics for the archaeologist. Carnegie Institution Publication 609. Washington D.C.

TARRAGÓ, M., 1975. Panorama arqueológico del sector septentrional del valle Calchaquí, Salta. Actasy Trabajos del $1^{\text {er }}$ Congreso Nacional de Arqueología Argentina, pp. 221-233. Buenos Aires. 


\section{Lidia BALdini, Marina Sprovieri}

1980. Los asentamientos aldeanos tempranos en el sector septentrional del valle Calchaquí, provincia de Salta, y el desarrollo agrícola posterior. Estudios de Arqueología 5: 29-53.

1996. El Formativo en el Noroeste Argentino y el alto valle Calchaquí. Revista del Museo de Historia de San Rafael 23 (1/4): 103-119.

TARRAGÓ, M. y M. DE LORENZI, 1976. Arqueología del valle Calchaquí. Etnia 23-24: 1-35.
TARRAGÓ, M. y P. DÍAZ, 1972. Sitios arqueológicos del valle Calchaquí. Estudios de Arqueología 1: 49-62.

TARRAGÓ, M., M. T. CARRARA y P. DÍAZ, 1979. Exploraciones arqueológicas en el sitio SSalCac 14 (Tero), valle Calchaquí. Antiquitas 2: 231-242. 